\title{
Análisis del uso del precedente en fallos del Tribunal Contencioso Administrativo del Valle del Cauca
}

\begin{abstract}
Alexander Atehortúa Rizo
Since 1991 the administrative jurisdiction is in charge of judging cases that involve the state's responsibility in relation to public service failures. This article presents the methodology and conclusions of a research project, which had the objective of studying the jurisprudence of the Administrative Court of Valle del Cauca in its treatment of lawsuits against the State, especially in cases related to economic prejudices arising from crises in financial cooperatives and cases of deaths, which occurred in penitentiaries.
\end{abstract}

\section{Introducción}

Desde antes de la vigencia de la Constitución de 1991 y en virtud del incremento de la actividad estatal en la prestación de servicios públicos, nuestro sistema jurídico aceptó que el desarrollo de la teoría de la responsabilidad estatal se realizara a través de la jurisprudencia de la jurisdicción contenciosa administrativa, en contraposición a la tradición iuspositivista colombiana. La función del juez contencioso era anteriormente desempeñada mediante la interpretación de los principios constitucionales de la Carta de $1886^{1}$ y la aplicación de la jurisprudencia que paulatinamente producía el Consejo de Estado. Actualmente, la labor de administrar justicia del juez contencioso administrativo en Colombia se encuentra regida por los preceptos constitucio-

\footnotetext{
${ }^{1}$ En especial del Art. 16 de la Constitución de 1886 modificado por el Acto Legislativo núm. 1 de 1936 Art. 9, el cual establecía lo siguiente: "Las autoridades de la república están instituidas para proteger a todas las personas residentes en Colombia, en sus vidas, honra y bienes, y para asegurar el cumplimiento de los deberes sociales del Estado y de los particulares".
} 
nales $^{2}$ y legales ${ }^{3}$ que regulan la función judicial. Si bien el establecimiento de la cláusula de responsabilidad estatal en el Art. 90 de la Constitución de 1991 concibió de manera expresa la responsabilidad del Estado en el ordenamiento jurídico colombiano, el desarrollo de sus elementos continuó en manos de la jurisprudencia de la Corte Constitucional y en especial de la producida por la jurisdicción contencioso administrativa principalmente a través del Consejo de Estado, esta última por ser en principio la encargada de dirimir los conflictos entre los particulares y el Estado (Art. 82 C.C.A.).

La actividad administrativa de un Estado en vía de desarrollo como el colombiano está sometida a factores como la austeridad presupuestal, los problemas de orden público, la burocracia y la corrupción, entre otros. A pesar de estos factores, la Constitución es clara al exigir el cumplimiento de los derechos y garantías de las personas, como también la promoción de la prosperidad general. (Art. 2).

El periódico El País de Cali en septiembre de 2005 titulaba en un artículo que la responsabilidad del Estado se ha convertido en "toda una feria de billones". Según este diario, las pretensiones de los demandantes para ese entonces "superaban los $\$ 71$ billones de pesos, equivalentes al 70\% del presupuesto nacional". Además señalaba que "más de 3.200 acciones han sido instauradas contra la Nación por la privación de la libertad de personas inocentes. Se calcula que el Estado perdería entre el 30\% y el 50\% de los casos". Este artículo evidencia la importancia que tienen las decisiones judiciales en la ejecución del presupuesto nacional y permite exponer las preocupaciones institucionales que genera la posible materialización de la totalidad de pretensiones. Las cifras que presenta esta noticia deben ser interpretadas en contexto y teniendo en cuenta varios factores jurídicos que influyen de forma determinante, como lo son el trámite de las demandas, la cantidad de dinero y la forma de pago que debe adoptar el Estado. Entre estos factores podemos considerar:

1. La relación entre el número en aumento de procesos judiciales que llegan a reparto al Consejo frente al número limitado de consejeros que son competentes para conocer de los casos según su naturaleza ha congestionado los despachos judiciales, teniendo como consecuencia que los hechos por los que se condena al Estado en una sentencia hayan ocurrido mucho tiempo atrás. 2. Como consecuencia de la demora en las decisiones, si bien no todas las pretensiones son despachadas favorablemente, las que

\footnotetext{
${ }^{2}$ Especialmente los artículos 116, 228 y siguientes.

${ }^{3}$ Ley 270 de 1996 artículos. 1, 2, 3, 4, 5, 7, 9, 34 y siguientes, Decreto 01 de 1984 -Código Contencioso Administrativo- artículos 1, 82, 86, 106, entre otras).
} 
son admitidas deben sufrir un reajuste financiero de acuerdo a la naturaleza del proceso.

3. La acción de repetición, consagrada en el inciso segundo del Art. 90 de la Constitución y desarrollada en la Ley 678 de 2001, implica que la persona jurídica de derecho público pueda trasladar al funcionario la carga de las condenas cuando la conducta que la generó sea consecuencia de dolo o culpa grave de él.

El artículo mencionado ampliaba las consideraciones sobre la congestión judicial al retomar palabras del consejero Germán Rodríguez Villamizar, para ese momento presidente del Consejo de Estado, quien indicaba que cada uno de los cinco magistrados que conforman la sesión tercera tenía para fallo más de dos mil querellas, que representaban millonarias reclamaciones: "Son cinco magistrados y cada uno maneja más de dos mil negocios para sentencia. Ha habido semanas en donde al hacer un reparto ordinario entregan 130 negocios, más o menos, y de esos salen 74 negocios para dictar fallo". Lo anterior demuestra que el recurso humano en la jurisdicción contenciosa tiene un límite, lo cual se ve reflejado en la cantidad y calidad de sentencias que en ella se producen.

Hasta aquí se han indicado algunos factores que podrían influir en las decisiones del juez contencioso administrativo. Estos factores se encuentran alrededor de la función del juez, presionándolo para que sus fallos tengan una coherencia con todas las variables jurídicas y extrajurídicas involucradas, pero en lo posible manteniendo una armonía en el aparato judicial mediante el uso estable de precedentes, que con el actual esquema jurídico nacional han tomado el carácter de vinculantes. En algunos casos la balanza se inclina privilegiando la integridad del patrimonio estatal y en otras los derechos patrimoniales de los ciudadanos, pero en últimas la distribución de las cargas es entregada al juez, confiando que en uso de su sabiduría jurídica optará por privilegiar los mandatos sociales que optimicen los mandatos constitucionales. Como complemento de su función judicial y dado el complejo contexto económico y social de la actividad administrativa, el juez contencioso debe desarrollar su labor con elementos críticos y un amplio conocimiento de los preceptos sobre la responsabilidad estatal. En este sentido, el coherente proceso argumentativo que desarrolle para realizar una sentencia que responda a los retos de este contexto es el lazo efectivo entre la titularidad y el goce de los derechos de las personas afectadas por la actividad estatal.

El análisis jurisprudencial realizado en el año 2006 a partir de una muestra de 66 sentencias de acciones de reparación directa por falla en el servicio fruto de una omisión administrativa, tuvo como objetivo verificar las reglas y criterios que aplica el Tribunal Contencioso Administrativo del Valle del Cauca en sus 
fallos de reparación, así como también la aplicación que hace de la jurisprudencia constitucional y contenciosa en ellos para evidenciar el estado actual en la región del uso del precedente en esta materia. Los referentes analíticos claves que se tomaron para la investigación fueron: a. La calidad del actor; b. La entidad demandada; c. La inclusión de citas jurisprudenciales explícitas o implícitas en los fallos; d. El uso de la jurisprudencia; y e. La decisión adoptada. Como metodología de este artículo, expondremos primero los resultados de los referentes analíticos revisados en las sentencias, comprendidas principalmente entre los años 2002 y 2003, de los procesos de reparación directa del tribunal y revisadas en el desarrollo de la investigación realizada por el autor de este texto en el año 2006. Posteriormente, como segundo punto, dedicaremos una especial atención a dos líneas jurisprudenciales halladas en la muestra y trazadas por esta corporación: 1. La línea de las sentencias contra el Instituto Nacional Penitenciario y Carcelario (INPEC), por ser la entidad estatal con más condenas encontradas en la muestra de sentencias; y 2. La línea de las sentencias contra DANCOOP, por el manejo del precedente propio que ha realizado en ellas el tribunal. Al final, recapitularemos los datos encontrados para exponer brevemente los hallazgos de la investigación.

\section{Resultados de los referentes analíticos}

a. Calidad del actor

Este referente sirvió para verificar la calidad y proporción de actores que reclaman, a través de la jurisdicción contencioso administrativa, la responsabilidad del Estado. El concepto de afectado hace referencia a toda persona que experimenta daño o menoscabo, tanto en lo material como en lo moral, por culpa o negligencia de otra, contra la cual puede ejercitar la correspondiente acción. La calidad de actores hace referencia a su relación frente al daño, es decir, se verificó si eran afectados directos, indirectos o de ambas clases los que concurrían al proceso. ${ }^{4}$

La calidad en la que acude cada uno de estos actores cobra importancia si se analiza la proporción en que se incrementa el monto de las pretensiones en razón a un mayor número de afectados reclamando en una misma demanda. Así, en las demandas, mientras que el afectado directo usualmente es una sola persona, los afectados indirectos, en la mayoría de las sentencias revisadas, son un grupo de personas que comparten vínculos de parentesco con el afectado directo (padres, madres, hijos, entre otros).

En la investigación se encontraron los tres tipos posibles de situaciones

${ }^{4}$ Ver, entre otras, Consejo de Estado, Sentencias de noviembre 1 de 1991, y Sentencia del 18 de febrero de 1999 . 
referente a la calidad en que el actor acude al proceso: 1 . Acude solamente el afectado directo; 2 . Acuden los afectados indirectos; y 3. Acuden afectados directos e indirectos. La situación que más se presenta es la segunda, en 39 fallos ( $59 \%$ de la muestra) sólo acuden los afectados indirectos; le sigue la tercera situación con 17 fallos (26\%) y por último está la primera situación con 10 fallos (15\%). Como hipótesis que justifique esta magnitud en la concurrencia de afectados indirectos en las demandas se puede plantear que hay una pretensión generalizada, posiblemente auspiciada por los apoderados judiciales de los demandantes, de obtener una mayor indemnización por el daño ocasionado en virtud de la actividad estatal. Por ejemplo, en algunos casos, además de los perjuicios morales ocasionados, se reclama el lucro cesante de la persona fallecida, la cual, al momento de su deceso, no se encontraba trabajando. ${ }^{5}$

En los 39 fallos revisados donde concurrieron sólo los afectados indirectos, la constante es que los ascendientes, descendientes o cónyuges de la víctima concurrían al proceso para obtener una indemnización por perjuicios morales. Cuando simultáneamente acuden los afectados directos e indirectos, la persona directamente afectada no falleció, pero sí sufrió un perjuicio físico o moral que le impidió continuar con sus funciones habituales en el hogar o lugar de trabajo. Cuando el afectado directo es la única persona que acude al proceso, usualmente sucede que los perjuicios reclamados son principalmente de carácter patrimonial. En estas situaciones, aunque no se evidencia un perjuicio moral de manera explícita, esto no significa que tal perjuicio no se pueda valorar. En estos casos, según las consideraciones del tribunal, todo depende de lo que se logre probar en el proceso.

b. Entidad demandada

Este referente se utilizó para verificar cuál era la persona de derecho público demandada. En la muestra tomada se identificaron 26 diferentes personas jurídicas de derecho público demandadas. Entre ellas se encontraron municipios, empresas sociales del Estado, departamentos administrativos, empresas industriales y comerciales del Estado, entre otros. Las entidades involucradas en un mayor número de sentencias fueron el Instituto Nacional Carcelario y Penitenciario (INPEC) con 15 fallos (23\% de la muestra) y el ejército nacional con 10 fallos (15\%). Le siguen el Instituto de Seguros Sociales (I.S.S.) con 9 fallos (14\%), el municipio de Santiago de Cali con 7 fallos (11\%) y la policía

${ }^{5}$ La Corte Constitucional en Sentencia C-197/93 M.P. Dr. Antonio Barrera Carbonell se pronunció acerca de la reparación de las víctimas por parte del Estado de la siguiente manera: "(...) que la reparación del daño con fundamento en la responsabilidad estatal no puede constituir una fuente de enriquecimiento. El resarcimiento del perjuicio, debe guardar correspondencia directa con la magnitud del daño causado, mas no puede superar ese límite". En esta sentencia se estudia la constitucionalidad de las medidas de apoyo a las víctimas de atentados terroristas (Decreto 444 de 1993). 
nacional con 5 fallos (8\%). El cúmulo de estas sentencias corresponde al 70\% de la muestra.

La mayoría de sentencias contra el INPEC son fruto de demandas de reparación directa por la muerte de personas que se encuentran privadas de la libertad en virtud de una orden judicial en las instalaciones carcelarias y penitenciarias que el instituto administra. En el caso de las sentencias contra el ejército nacional, las demandas son fruto de la omisión en el deber de retornar a la sociedad a las personas que prestan servicio militar en condiciones iguales o similares con las que ingresaron al servicio o por los daños ocasionados con armas de dotación oficial. Contra el municipio de Cali, las sentencias son fruto de acciones por omitir la reparación de infraestructura vial y de servicios públicos, cuyo deficiente estado genera daños a los particulares. Contra el I.S.S., en todos los casos las sentencias son fruto de demandas por negligencia en la prestación del servicio de salud en virtud de la omisión de realizar un procedimiento de manera oportuna, o de no emplear todos los tratamientos y procedimientos médicos para preservar la salud de los pacientes afectados.

Además de estas reclamaciones, se aprecia que en muchos casos donde resulta condenada la entidad, la defensa jurídica recibida por ésta no ha sido la más adecuada u oportuna. En algunos casos los apoderados del Estado invocan causales de exoneración exclusivas de la responsabilidad civil extracontractual que no operan para los casos de responsabilidad estatal, mientras que en otros contestan la demanda extemporáneamente. Esto indica que además de los hechos que generan la responsabilidad estatal, las actuaciones procesales que realizan inadecuadamente los apoderados de las entidades estatales contribuyen a que el Estado sea condenado. ${ }^{6}$

c. Cita jurisprudencial

Mediante este referente se verificó el uso de precedentes de manera explícita o implícita, ya fueran propios o de una alta corte, en los fallos revisados. Se dice que el uso es explícito porque hay una referencia puntual del fallo que es fuente del precedente (fecha, número de radicación, nombre del magistrado, etc.), mientras que si es de manera implícita, la referencia es general y sin determinar la fuente jurisprudencial. El panorama de este referente es el siguiente: de la muestra total, 50 sentencias ( $76 \%$ de la muestra) contienen una cita jurisprudencial explícita o implícita, mientras que en las 16 restantes (24\%) no la hay. Con relación a las 50 sentencias que contenían citas jurisprudenciales, se pudo identificar que 41 de ellas contenían una cita jurisprudencial

${ }^{6}$ Esta, por ejemplo, es una de las preocupaciones principales que se exponen en el documento CONPES 3250 de 2002, mediante el cual se sugirió la creación de la Dirección de Defensa Judicial de la Nación, 
con alguno de estos datos: referencia de la corporación, fecha o número de expediente; mientras que en las 9 restantes, la referencia era implícita, es decir que se hacía referencia a "la jurisprudencia" en general.

En la verificación se encontró que el Consejo de Estado es la entidad más citada dentro de los fallos del tribunal. Las razones de este porcentaje pueden ser atribuibles a cualquiera de estos motivos: 1. El Consejo de Estado es el tribunal supremo de la jurisdicción contencioso administrativa; ${ }^{7}$ y 2. En virtud de la competencia que tiene el Consejo de Estado como máximo tribunal de esta jurisdicción, en especial la sección tercera, su jurisprudencia se ha especializado en el tema. En contraste, dentro de todas las sentencias de la muestra, sólo en una ocasión se citó la jurisprudencia de la Corte Constitucional. Esto se hizo para considerar el tema de los ejercicios físicos que deben realizar las personas que prestan el servicio militar. ${ }^{8}$ Pero frente a los elementos de la responsabilidad estatal (hecho, daño, nexo causal, falla en el servicio, etc.), el tribunal no toma elementos o consideraciones hechas por la jurisprudencia de la Corte. ${ }^{9}$

Un dato particular encontrado en la investigación fue que, en muchas ocasiones, cuando se cita un precedente contenido en los extractos de la revista Jurisprudencia y Doctrina, no se hace mención al número de sentencia, expediente del caso o corporación que expide el fallo, sino al número de publicación de la revista. Esto eventualmente puede restringir el rastreo de la fuente jurisprudencial sólo a quien tenga acceso a la publicación.

\section{d. Uso de la jurisprudencia}

Mediante este referente se estableció cuál era el uso argumentativo de la jurisprudencia evidenciado en los fallos. En especial se verificó si el uso dado a la jurisprudencia era el de su reducción a premisas mayores para adecuarlas a los hechos del caso, si esta era usada como argumento de autoridad, o por el contrario, si era utilizada como una herramienta argumentativa dinámica para establecer una posición crítica frente a los hechos y consideraciones del caso y del precedente mismo.

El uso de la jurisprudencia como premisa para emitir el fallo implica que la cita jurisprudencial utilizada se redujo a una forma de una premisa mayor que luego fue usada en un proceso subsunción silogística para emitir el fallo. Como afirma Diego López, este es el uso común que se le ha dado a la jurisprudencia en Colombia, donde se mutilan los hechos y consideraciones de las

\footnotetext{
${ }^{7}$ Num. 1 Art. 237 Constitución Política, Ley 270 de 1996 Art. 34 Art. 89 C.C.A.

${ }^{8}$ Sentencia T-351/96 M.P. Dr. José Gregorio Hernández Galindo.

${ }^{9}$ Sobre este punto, la Corte Constitucional sí se ha pronunciado en varios fallos acerca de la responsabilidad estatal. Se puede consultar, entre otras, las sentencias C-058/93, C-197/93, C-542/93, C-366/94, C-296/95, T-171/94, T-251/95.
} 
sentencias para extractar la consideración (o pasaje) que sirve para el caso. Esto, de acuerdo a este autor, ha sido consecuencia del tradicionalismo de fuentes. ${ }^{10}$ Los resultados obtenidos en esta variable muestran que en el 100\% de las sentencias revisadas que contenían cita jurisprudencial el uso dado es el de premisa mayor para proferir el fallo. Esto muestra que la tradición jurídica colombiana, con respecto al uso del precedente, poco se ha modificado dentro del tribunal y que aún no hay un rasgo apreciable de variación.

Una hipótesis que se puede plantear como barrera para el cambio en el uso legítimo de la jurisprudencia es que los funcionarios que trabajan en el tribunal están constantemente ocupados en los trámites procesales, razón por la cual la construcción de líneas jurisprudenciales para cada caso y el uso de nuevos precedentes, en un principio, puede ser un proceso que requiera mucho tiempo y contribuya a agravar el problema de la congestión judicial. ${ }^{11}$

e. Decisión adoptada

A través de este referente se verificó si hubo alguno los siguientes eventos en cada sentencia de la muestra: estimación completa o parcial de las pretensiones, desestimación o inhibición. El Estado resultó condenado plenamente en 16 de las sentencias revisadas y parcialmente en 12, la suma de estas dos cantidades representa el $42 \%$ de la muestra. En el 58\% restante el Estado fue absuelto. Independientemente de las razones de cada fallo, en el ámbito de la muestra se aprecia que el Estado es absuelto de cualquier responsabilidad en más de la mitad de las demandas.

\section{Líneas jurisprudenciales trazadas por el tribunal}

En la investigación del año 2006, de las 66 sentencias extraídas del Tribunal Contencioso Administrativo del Valle del Cauca, se encontraron dos líneas jurisprudenciales que, a pesar de encontrarse solamente en una fracción del material revisado, permiten realizar un breve análisis sobre los derechos en disputa, pues en tales casos se discuten cuestiones de gran responsabilidad patrimonial para el Estado y se aprecia una reiterada posición en la decisión.

\footnotetext{
10 Medina, Diego Eduardo, El derecho de los jueces, Editorial Legis, Bogotá D.C., 2000, p. 94.

${ }^{11}$ La congestión judicial del tribunal es evidente. En sólo acciones de reparación directa se archivaron cerca de 820 procesos entre los años 2003 a 2005, de acuerdo a una estadística proporcionada por la relatoría de esta corporación. Esto significa que durante cada año de ese período se archivaron en promedio 273 procesos sólo de reparación directa. Si se tiene en cuenta que los magistrados del tribunal también conocen de acciones de tutela, populares, de nulidad, nulidad y reestablecimiento del derecho, contractuales, entre otras, las cifras en el trámite de procesos se incrementan drásticamente.
} 
Los casos revisados dentro de la muestra y que componen estas líneas jurisprudenciales tratan, en primer lugar, sobre demandas contra el Departamento Administrativo de Cooperativas (DANCOOP), en virtud de su supuesta omisión en el deber de vigilancia y control de las entidades cooperativas que ejercían funciones financieras cuando estas entraron en cesación de pagos, intervención estatal o liquidación obligatoria. En segundo lugar encontramos demandas contra el Instituto Nacional Carcelario y Penitenciario (INPEC) por la muerte de reclusos en las instalaciones penitenciarias, cuya administración le ha sido encargada.

Como aspectos relevantes para su análisis, encontramos que en la primera línea se aprecia una aplicación directa del precedente realizado por el mismo tribunal, mientras que en la segunda, el INPEC es la entidad estatal con más sentencias en contra, entre aquellas revisadas en la investigación. Cada una de estas entidades estatales desarrolla sus funciones en un campo distinto del aparato estatal. Sin embargo, la magnitud de su función les impone una gran responsabilidad patrimonial. Por ejemplo, en el caso de DANCOOP, su función de control y vigilancia le exige estar al tanto de las incidencias del sector cooperativo en Colombia, el cual aporta casi el 5\% del PIB del país. ${ }^{12}$ En el caso del INPEC, con cerca de 63.656 reclusos en las instalaciones carcelarias del país, ${ }^{13}$ su capacidad de vigilancia y control es insuficiente para garantizar la protección y seguridad de las personas recluidas en estas instalaciones donde hay un $21.1 \%$ de hacinamiento.

\section{a. Demandas contra DANCOOP}

El Departamento Administrativo de Cooperativas (DANCOOP) ${ }^{14}$ de acuerdo al Art. 1 de la Ley 24 de 1981 era la entidad encargada de dirigir y ejecutar la política cooperativa del Estado, colaborar en la planeación económica cooperativa y ejercer vigilancia y control sobre las sociedades cooperativas, los organismos cooperativos, los institutos de financiamiento, educación, investigación y desarrollo cooperativo, entre otras funciones. En 1995 las cooperativas vinculadas al sector financiero del país lograron captar y movilizar algo más de la sexta parte del total del ahorro nacional, contando, aproximadamente, con tres millones de usuarios alrededor del país. En virtud de esta captación

\footnotetext{
12 Fuente http://www.dansocial.gov.co

${ }^{13}$ Estadística del INPEC a Abril de 2006. Fuente http://www.inpec.gov.co/estadisticas.php

${ }^{14}$ Antes de la Ley 454 de 1998, el departamento encargado del control de los entes cooperativos se denominaba Departamento Administrativo Nacional de Cooperativas (DANCOOP). Posterior a esta ley, cambió su nombre a Departamento Administrativo Nacional de la Economía Solidaria (DANSOCIAL), el cual continuó desarrollando las mismas funciones de vigilancia y control a las cooperativas. Al asumir DANSOCIAL las funciones de DANCOOP, las demandas intentadas contra este último deben ser intentadas contra el primero.
} 
de usuarios y capitales, el cooperativismo ganó independencia y autonomía al consolidar sus propias fuentes de financiación. Esta captación marcó unas buenas perspectivas de crecimiento para el sector cooperativo en este año, pero la realidad fue otra. En 1996, las proyecciones financieras internas del sector dieron cuenta de su situación real: el crecimiento proyectado no se veía reflejado. Ante la necesidad de mejorar la situación, algunas entidades cooperativas recurrieron al excesivo endeudamiento como herramienta para tener mayor solvencia. En otras entidades, prácticas administrativas internas, como el maquillaje de resultados, mantenían escondida la realidad de las empresas esperando una mejoría en el sector. En 1998 se evidenció plenamente la crisis del sector cooperativo: se liquidaron 49 entidades cooperativas financieras, se intervinieron otras 9 y casi 800.000 ahorradores de este sector resultaron afectados. ${ }^{15}$

De acuerdo a la Confederación de Cooperativas de Colombia (Confecoop), algunas de las causas que llevaron a la crisis del sector cooperativo fueron la recesión de la economía colombiana, la inadecuada supervisión y vigilancia estatal, la ausencia de normas reguladoras del sector y las fallas administrativas dentro de las cooperativas, entre otras. Si bien los estudios realizados sobre el tema no son concluyentes sobre la causa efectiva de la crisis del sector cooperativo, es evidente que ellos coinciden en que una de ellas pudo ser la inactividad en la vigilancia y control por parte de DANCOOP, lo cual, para efectos jurídicos, se podría traducir en una falla del servicio. La causa de esta falla sería entonces la omisión en el ejercicio de las funciones legales de vigilancia y control por parte de este departamento administrativo. Sin embargo, al ser DANCOOP una autoridad administrativa, cuyas funciones de vigilancia y control están claramente determinadas en la Ley 24 de 1981, el hecho de afirmar a través de estudios particulares que su inactividad fue una de las causas que llevó a la crisis del sector cooperativo no es fundamento suficiente para declarar la responsabilidad administrativa del Estado, porque esta debe probarse a través de un procedimiento judicial ante la jurisdicción contencioso administrativa. Esto fue exactamente lo que intentaron varios actores y sobre lo cual el tribunal decidió de la manera descrita a continuación.

\section{Línea jurisprudencial trazada por el Tribunal Contencioso Administrativo del Valle del Cauca en demandas contra DANCOOP}

En la investigación de 2006 fueron analizadas cuatro sentencias que resolvían disputas contra DANCOOP. Las demandas de reparación tenían como

${ }^{15}$ Padilla Piraquive, Martha Rocío, Crisis del cooperativismo financiero en Colombia, 1996-1998, Primera edición, Universidad Pedagógica Nacional, Bogotá D.C., 2005. 
fundamento el perjuicio individual causado a los accionantes de las demandas, que en todos los casos eran ahorradores de entidades cooperativas, al perder el capital invertido en las entidades ante la presunta omisión en las funciones de vigilancia y control que debió ejercer DANCOOP sobre las cooperativas bajo su supervisión. El argumento central de las demandas radicaba en que DANCOOP debió, en ejercicio de sus funciones de vigilancia y control, verificar que las cooperativas estaban realizando manejos indebidos del capital de los ahorradores para realizar una oportuna intervención y evitar la cesación de pagos o su trámite de liquidación obligatoria. Dada la naturaleza privada de las entidades cooperativas, el tribunal expone en las consideraciones de sus fallos que la obligación de vigilancia y control de DANCOOP no era la de cogestionar la dirección de la entidad. Esto significa que las funciones de este departamento administrativo estaban centradas en encontrar irregularidades en el desarrollo de las actividades financieras reportadas por las cooperativas, más no en actuar como veedor de las decisiones administrativas internas de cada una de ellas. El hecho de que las cooperativas hayan entrado en iliquidez se debió a decisiones de sus administradores, las cuales fueron en algunos casos ilegales y en otros erradas, pero que en su momento no tenían que ser de conocimiento de DANCOOP. El tribunal también considera en todos los casos que la responsabilidad de DANCOOP habría sido distinta si, conociendo las irregularidades internas de las cooperativas, no hubiera tomado acciones preventivas como la intervención de la entidad, en cuyo caso sí se habría configurado una falla en el servicio por omisión administrativa. Por esta misma razón, el tribunal niega las pretensiones en las cuatro sentencias revisadas.

Adicional a estos argumentos, el tribunal también afirma que el daño causado a los demandantes no está identificado plenamente, ya que las cooperativas donde se encontraban depositados los ahorros de los demandantes aún se encontraban en proceso de liquidación al momento de la sentencia. Por lo tanto, el perjuicio real de los demandantes estaba sujeto a la diferencia entre el monto perdido y lo que se pagara como remanente a los ahorradores al final de este trámite.

Una característica recurrente en los cuatro fallos es la aplicación del precedente propio del tribunal. La razón de esta aplicación puede obedecer a dos factores: 1. La ausencia al momento de los fallos de jurisprudencia del Consejo de Estado en materia de la responsabilidad de DANCOOP ante la iliquidez de las cooperativas. ${ }^{16} 2$. En vista de lo anterior, la única referencia

\footnotetext{
${ }^{16}$ En búsquedas realizadas a través de diferentes bases de datos, encontramos que el Consejo de Estado al momento de desarrollar la investigación, aún no había realizado un pronunciamiento de fondo sobre estos casos contra DANCOOP. Esto se debe a que los hechos que configuran las pretensiones de las demandas son relativamente "recientes". Se dice que son recientes porque la
} 
jurisprudencial con la que contaban los magistrados del tribunal para fallar sus casos era la que ellos mismos o sus colegas habían desarrollado en sentencias anteriores sobre casos similares.

Si bien el tribunal ha producido sus propias reglas y criterios para los casos en donde DANCOOP es demandado, hay que tener en cuenta como factor extrajurídico en estos procesos que a nivel nacional la cantidad de personas afectadas por las crisis del sistema cooperativo fácilmente puede superar el millón de usuarios, y que el monto adeudado a ellas puede llegar a tener un valor equivalente al 2\% del PIB. El efecto de una condena contra el Estado en este sentido podría configurar un precedente que serviría de fundamento para otras demandas que, si son falladas en contra del Estado, generarían un desequilibrio presupuestal en tanto que el Estado deberá disponer de las partidas necesarias para el pago de las condenas. Igualmente, el trámite de una eventual avalancha de demandas congestionaría el aparato judicial. En este sentido, la controversia aún no ha tenido un pronunciamiento de fondo por parte del Consejo de Estado, razón por la cual no hay un parámetro jurisprudencial en la región distinto al del tribunal para realizar un contraste a la línea jurisprudencial encontrada en esta investigación.

\section{b. Demandas contra el INPEC}

El servicio público carcelario y penitenciario hace parte de un conjunto de servicios públicos para la administración de las instalaciones penitenciarias y vigilancia de los prisioneros, ligados a la función judicial en el campo penal y a la función administrativa del Estado con el fin de satisfacer las funciones de la pena y las medidas de seguridad aplicadas a los infractores de la ley penal. En este sentido, los usuarios del servicio carcelario y penitenciario pueden ser clasificados en dos grupos: 1. Las entidades estatales que conducen las etapas de investigación y juzgamiento. 2. Las personas objeto de las decisiones judiciales que ven restringido su derecho a la libre locomoción y son confinadas en las instalaciones penitenciarias.

El servicio público carcelario y penitenciario es prestado a través del Instituto Nacional Carcelario y Penitenciario (INPEC), el cual fue creado por el Decreto 2160 de Diciembre 30 de 1992 en desarrollo del Art. 20 transitorio de la Constitución como un "establecimiento público adscrito al Ministerio de Justicia (hoy Ministerio del Interior y de Justicia), con personería jurídi-

mayoría de problemas internos de las cooperativas comenzaron a manifestarse en el año de 1998. Mientras se intentaban las acciones de reparación directa pudo transcurrir un término de dos años. Si a estos dos años sumamos el tiempo que toma al tribunal decidir la primera instancia, para luego sumar el tiempo del trámite de apelación ante el Consejo de Estado, se infiere que un pronunciamiento definitivo aún está lejos de ser emitido.

\section{PRECEDENTE}


ca, patrimonio independiente y autonomía administrativa". ${ }^{17}$ Sus funciones esenciales son las de satisfacer las necesidades de la pena, que incluyen entre otras la protección al condenado y el cumplimiento de la política carcelaria y penitenciaria. Además, ejerce la dirección, administración y control de los centros carcelarios y penitenciarios del orden nacional, como también la vigilancia y custodia de estos, aplicando lo dispuesto en la Ley 63 de 1993 (Código Nacional Penitenciario y Carcelario).

De acuerdo a estadísticas del INPEC, en el año 2006 esta entidad controlaba 139 centros carcelarios y penitenciarios en todo el país, los cuales tenían capacidad para albergar 52.573 reclusos. En el mes de abril de 2006 se encontraban recluidos en las cárceles de Colombia cerca de 63.656 personas. El sobrecupo de 11.083 reclusos equivale aproximadamente a un $21.1 \%$ de hacinamiento. ${ }^{18}$ En el aspecto presupuestal, en el año 2005 su presupuesto total era de $\$ 532.463 .370 .998$.oo aproximadamente. Sin embargo, la información sobre el costo de las condenas realizadas en virtud de acciones de reparación directa no se encuentra discriminada en esta información.

La jurisprudencia ${ }^{19}$ y la doctrina administrativa al estudiar la falla en la prestación del servicio carcelario, han determinado que cuando el particular se encuentra detenido bajo órdenes de las autoridades públicas, la obligación de protección que sobre ellas recae se convierte en una obligación de resultado, presumiéndose la responsabilidad de la administración con la sola prueba de que la víctima no ha sido reintegrada a la sociedad en las mismas condiciones en que ingresó a su detención.

\section{Línea jurisprudencial trazada por el Tribunal Contencioso Administrativo del Valle del Cauca en demandas contra el INPEC}

En vista de la alta población carcelaria que maneja el INPEC, de su insuficiente pie de fuerza para controlar todas las incidencias dentro de los planteles penitenciarios y de las condiciones de hacinamiento ${ }^{20}$ en que viven los prisioneros, resulta razonable que esta sea una de las entidades públicas más demandadas por reparación directa debido a daños ocasionados a los reclusos, tal como se observa en la muestra obtenida en desarrollo de la investigación. Las estadísticas del Observatorio de los Derechos Humanos en Colombia entre los

\footnotetext{
${ }^{17}$ Art. 2 D. 2160 de 1992.

${ }^{18}$ Fuente http:// www.inpec.gov.co

${ }^{19}$ Consejo de Estado, Sentencia del 11 de febrero de 1993, Sentencia del 7 de diciembre de 1994, Sentencia de diciembre 6 de 1998, Sentencia del 22 de agosto de 1996, entre otras.

${ }^{20}$ Sobre este tema la Corte Constitucional se pronunció en la Sentencia T-153/98 M.P. Dr.
} 
años 1998 y 2001 muestran que anualmente mueren en situaciones violentas en las cárceles de Colombia un promedio de 166 personas. Además, el hacinamiento que se registra en las cárceles implica que la capacidad de vigilancia y control se vea mermada en relación al número de guardianes dispuestos para estas tareas. ${ }^{21}$ Las situaciones violentas pueden corresponder a motines entre los presos, a ajustes de cuentas dentro de los planteles penitenciarios o a personas que han optado por el suicidio, entre otras situaciones.

Cuando el INPEC es demandado ante el tribunal, en muchas ocasiones no contesta las demandas o las contesta de manera extemporánea. Cuando contesta las demandas, invoca la "fuerza mayor", sustentada en la incapacidad de ejercer control total de las instalaciones penitenciarias, como causal de exoneración. Sin embargo, en las sentencias se consideró que su uso es inconducente para evitar la declaración de responsabilidad, por no ser ésta una causal exonerativa de responsabilidad estatal en este tipo de casos. Otro de los argumentos que esgrime el INPEC en sus defensas es el de la figura del "nivel medio del servicio", ${ }^{22}$ en virtud de la cual se pretende vincular las circunstancias fácticas en que se presta el servicio para buscar la exoneración de responsabilidad, o por lo menos mitigar el monto de la condena. Este argumento es siempre descartado en virtud de la posición trazada por la jurisprudencia administrativa sobre la falla en el servicio por muerte de reclusos.

De las quince sentencias revisadas en el año 2006 donde el INPEC era parte del proceso, en diez de ellas había pruebas suficientes para fallar el caso, en cuatro las pretensiones fueron desestimadas por no probar los hechos, el daño o el nexo causal, y en una el afectado no era un recluso, sino un contratista víctima de un hurto dentro de las instalaciones de un plantel. En las diez sentencias donde hubo pruebas suficientes para fallar el caso, el Tribunal Contencioso Administrativo del Valle del Cauca fue fiel a la jurisprudencia del Consejo de Estado en materia de responsabilidad estatal por la muerte de personas en las instituciones carcelarias.

El rigor en la apreciación de las pruebas en los cuatro casos que no se consideraron en la línea jurisprudencial impidió que en ellos se discutiera de

Eduardo Cifuentes Muñoz. En esta sentencia se consideró inconstitucional el estado de cosas en los establecimientos carcelarios. En ella consideran las estadísticas nacionales de la época sobre hacinamiento en las cárceles de Colombia.

${ }^{21}$ Esta situación de insuficiente pie de fuerza de personal penitenciario es también incluida en el informe sobre los centros de reclusión en Colombia del Alto Comisionado de las Naciones Unidas para los Derechos Humanos, oficina Colombia. Un ejemplo es que en la cárcel de Bellavista en Medellín, en el año 2001, solamente 160 guardianes cuidaban a aproximadamente 6.100 reclusos.

${ }^{22}$ Ver entre otras, Consejo de Estado, Sentencia del 4 de Agosto de 1998, Sentencia del 4 de Noviembre de 1993. 
fondo si en realidad hubo o no falla en el servicio. Por ejemplo, en uno de estos cuatro casos la persona afectada murió de una neumonía, presuntamente adquirida mientras estuvo recluida en la cárcel de Cali. En vista de no aparecer probado de forma conclusiva el hecho de haber contraído la enfermedad en el establecimiento penitenciario, el tribunal desvirtuó el nexo causal, lo cual bastaba para no declarar responsable al Estado. En otro de los casos no considerados la persona afectada por la muerte del recluso no pudo probar la relación afectiva con la víctima. En este caso, al no existir daño, el Estado no podía ser declarado responsable.

En síntesis, el tribunal es coherente en su línea de precedente al conceder a los afectados por la muerte de personas en las instalaciones penitenciarias una indemnización acorde a los perjuicios sufridos, pero en muchos casos el rigor probatorio al que someten los hechos impide que se realicen consideraciones de fondo acerca de las pretensiones y argumentos de las partes.

\section{Apreciaciones finales}

En la verificación de la existencia de factores extrajurídicos y criterios jurisprudenciales propios o de las altas cortes nacionales empleados por el Tribunal Contencioso Administrativo del Valle del Cauca en los fallos de acciones de reparación directa revisados durante la investigación de 2006, observamos que en los fallos no hay criterios extrajurídicos explícitos o implícitos que indiquen una tendencia de los magistrados a prever los efectos económicos que sus decisiones representarían al Estado. Ante la ausencia de tales criterios económicos en los fallos, se puede plantear como hipótesis que hay una fidelidad completa al imperio de la ley por parte de los magistrados del tribunal. A esto se suma la autonomía real que tiene en el ejercicio de su función judicial, pese a los factores que pueden llegar a matizarla (congestión en los despachos, déficit presupuestal del Estado, entre otros). En efecto, si por ejemplo vemos los casos donde mueren personas en las instalaciones penitenciarias en el Valle del Cauca, encontramos que hay una constante en reconocer la responsabilidad del Estado y reparar a las personas afectadas por la muerte de reos, pero sólo si se encuentra probada en el proceso la existencia de los elementos que configuran la responsabilidad del Estado.

En cuanto a los referentes analíticos, se encontró en la muestra que el uso dado a la jurisprudencia por el tribunal no va más allá de una cita, la cual es usada como un argumento de autoridad o como premisa mayor del fallo para sustentar una decisión, pero sin poder apreciar un cuestionamiento propio del tribunal sobre los valores, principios o derechos en juego en el precedente aplicado. Como se ha mencionado en este artículo, la labor de producción 
jurisprudencial no debe verse restringida en los jueces y magistrados de la jurisdicción contenciosa administrativa a una aplicación silogística de las reglas creadas por los máximos tribunales del país. La facultad creadora de reglas jurídicas en materia de la responsabilidad estatal debe ser explotada en una mayor proporción para contribuir con la evolución jurídica colombiana en esta materia. En este sentido hay cuestiones muy importantes en juego, como son el derecho de las personas a una correcta, eficiente y diligente administración de justicia.

Las demandas de reparación directa le cuestan al Estado tanto en su trámite como en los casos donde resulta condenado. A partir de la posición privilegiada que tiene el juez contencioso sobre las controversias entre los particulares y el Estado, puede exhortar a la administración a cumplir sus funciones de una manera más diligente y sensata con los usuarios. Esto por un lado para evitar tantos daños antijurídicos a los particulares y por otro para evitar el sometimiento de las controversias a tantos procesos de reparación directa. El hecho de que el tribunal aplique reglas de precedentes jurisprudenciales del Consejo de Estado en un 80\% de los fallos revisados en la investigación de 2006 indica un apego a lo considerado por el máximo órgano de la jurisdicción contencioso administrativa. En contraposición a esta tendencia, por ejemplo, el Tribunal Contencioso Administrativo de Cundinamarca se ha caracterizado por innovar y mantener posiciones críticas frente a temas de gran importancia jurídica. ${ }^{23}$ El desarrollo de una crítica sustancial al uso del precedente que emplea el juez contencioso administrativo del Valle del Cauca en sus fallos tendría un mayor significado si se apreciara un ejercicio argumentativo más crítico en cada una de sus sentencias.

\section{Bibliografía}

Bohórquez B., Luis F., Diccionario Jurídico Colombiano, Tomos I y II, Editora Jurídica Nacional, Quinta Edición, Bogotá D.C, 2003.

Henao, Juan Carlos, "El Daño: análisis comparativo de la responsabilidad extracontractual del Estado", en: Derecho colombiano y francés, Universidad Externado de Colombia, Bogotá D.C., 1998.

Lamprea Rodríguez, Pedro Antonio, Práctica contenciosa y administrativa, Ediciones Doctrina y Ley Ltda., Bogotá D.C., 1999.

\footnotetext{
${ }^{23}$ Un claro ejemplo de esta posición es la decisión que adoptó el tribunal contencioso de Cundinamarca como medida cautelar, en el trámite de una acción popular por los perjuicios que podría causar a los agricultores colombianos la firma del TLC con Estados Unidos. La medida consistió en impedir al presidente de la república firmar el tratado hasta tanto se compruebe que éste no vulnera los derechos constitucionales de los agricultores.
} 
López Medina, Diego Eduardo, El Derecho de los Jueces, Editorial Legis, Bogotá D.C., 2000.

López Obregón, Clara, Economía de los Derechos, Centro Editorial Biblioteca Jurídica Diké, Bogotá D.C., 2005.

Padilla Piraquive, Martha Rocío, Crisis del cooperativismo financiero en Colombia, 1996-1998, Primera edición, Universidad Pedagógica Nacional, Bogotá D.C., 2005.

Palacio Hincapié, Juan Ángel, Derecho Procesal Administrativo, III Edición, Librería Jurídica Sánchez R. Ltda., Bogotá D.C. 2002.

Ramos Acevedo, Jairo, Fundamentos de la Responsabilidad Extracontractual de la Administración Pública, Editorial Leyer, Bogotá D.C., 2004.

Saavedra Becerra, Ramiro, La Responsabilidad Extracontractual de la Administración Pública, Ediciones Jurídicas Gustavo Ibáñez, Bogotá D.C., 2003. 